\title{
Malaria Chemotherapy Control

\section{The Changing Landscape of Malaria Case Management in Uganda: Decades of Struggle with Evolving Malaria Case Management Strategies and Drug Policies}

Ambrose O Talisuna ${ }^{1,2,3,4}$, Jane Achan ${ }^{3,8}$, Albert Peter Okui ${ }^{5}$, Adoke Yeka ${ }^{3,8}$, Fred Kato $^{5}$, John Bosco Agaba ${ }^{5}$, Seraphine Adibaku ${ }^{5}$, John Bosco Rwakimari ${ }^{6}$ Sarah Staedke ${ }^{3,7}$, Grant Dorsey ${ }^{3,10}$, Moses R Kamya ${ }^{3,8}$ and Fred Wabwire- Mangen ${ }^{3,9}$

${ }^{1} \mathrm{KEMRI}$-Welcome Trust Research Program, Kenya

${ }^{2}$ Centre for Tropical Medicine, Nuffield Department of Clinical Medicine, University of Oxford, CCVTM, Oxford OX3 7LJ, UK

${ }^{3}$ Infectious Disease Research Collaboration in Uganda, Uganda

${ }^{4}$ World-wide Antimalarial Resistance Network (WWARN), Centre for Tropical Medicine, Nuffield Department of Clinical Medicine, University of Oxford, CCVTM, Oxford OX3 7LJ, UK

${ }^{5}$ Ministry of Health, National Malaria Control Programme, Uganda

${ }^{6}$ Abt Associates, Plot 3 Solent Avenue Mbuya, P.O. Box 37443 Kampala, Uganda

${ }^{7}$ London School of Hygiene and Tropical Medicine, UK

${ }^{8}$ Makerere University, School of Medicine, Uganda

${ }^{9}$ Makerere University School of Public Health, Uganda

${ }^{10}$ University of California San Francisco, USA

*Corresponding author: Ambrose O Talisuna, Centre for Tropical Medicine, Nuffield Department of Clinical Medicine, University of Oxford, CCVTM, Oxford OX3 7LJ, UK, Tel: +254 724-220-2; E-mail:atalisuna@kemri-wellcome.org

Received date: March 27, 2014; Accepted date: May 20, 2014; Published date: May 27, 2014

Copyright: (C2014 Ambrose TS, et al. This is an open-access article distributed under the terms of the Creative Commons Attribution License, which permits unrestricted use, distribution, and reproduction in any medium, provided the original author and source are credited.

\begin{abstract}
Background: Uganda has some of the highest reported malaria transmission rates in the world.

Methods: We reviewed published and un-published reports to provide a historical perspective and evolution of malaria case management strategies/policies in Uganda.

Review findings: In the 1990s, uncomplicated malaria treatment was hampered by widespread parasite resistance to chloroquine (CQ) and sulphadoxine-pyrimethamine (SP). Paradoxically, faced with this challenge, the country changed the first-line regimen, in 2000, to CQ+SP and adopted home based management of fever (HBMF) for children $<5$ years old. HBMF increased the proportion accessing CQ+SP within 24 hours from $7 \%$ in 2001 to $39 \%$ in 2003. However, after another policy shift, in 2004, to Artemether-Lumefantrine (AL), HBMF is to date implemented in only 34 of 112 districts. The private sector supports first treatment contact for $40-50 \%$ of fevers. However, engaging private sector providers remains challenging. Consequently, by 2011 , only $30 \%$ of febrile children took AL on the same/next day after symptom onset. In 2011 there was a policy shift from presumptive treatment to parasite-based diagnosis. Following the policy change, the proportion of tests by rapid diagnostic tests (RDTs) increased to about $55 \%$ compared to $30 \%$ by microscopy. However a major challenge remains clinician's adherence to test results. Reassuringly, AL remains efficacious. In 13 studies conducted between 2002 and 2010, the median PCR corrected day 28 efficacy was $98 \%$ (range: $71.9 \%-100 \%$ ). However, counterfeit medicines remain a threat and the lack of an effective phamacovigilance system is concerning. A recent study demonstrated that $39 \%$ of sampled artemisinin combination therapies were counterfeits.
\end{abstract}

Conclusion: Despite an increase in official development assistance over the last decade, by 2013 there remained gaps in national ambitions for universal access to prompt and effective treatment. A major challenge is the low profile of the national malaria control programme within the ministry of health structure which limits its capacity to coordinate multiple stakeholders. Secondly, there is a need for decentralized planning and implementation with greater involvement of the zonal, district, health facility and community levels. Finally, it will be critical to engage the challenging but very important private sector.

\section{Background}

Uganda has the third highest number of deaths from malaria in Africa, as well as some of the highest reported malaria transmission rates in the world [1,2]. The disease accounts for $30 \%-50 \%$ of outpatient visits and 15\%-20\% of hospital admissions [3]. Malaria infection in pregnant women leads to maternal anaemia, maternal death, miscarriage, pre-mature delivery, and low birth weight babies.
Four of the five plasmodia species that infect humans are present in Uganda. Over the last fifty years Plasmodium falciparum has remained the dominant parasite, accounting for over $90 \%$ of all infections [4].

Chloroquine (CQ) was the mainstay of therapy for uncomplicated falciparum malaria in most of sub-Saharan Africa until the late 1990s. With increasing parasite resistance to $\mathrm{CQ}$, there were policy shifts to Sulphadoxine-Pyrimethamine (SP), Amodiaquine (AQ), or 
Citation: Ambrose OT, Jane A, Albert PO, Adoke Y, Fred K, et al. (2014) The Changing Landscape of Malaria Case Management in Uganda: Decades of Struggle with Evolving Malaria Case Management Strategies and Drug Policies. Malar Chemoth Cont 3: 117. doi: $10.4172 / 2090-2778.1000117$

Page 2 of 16

combinations of $\mathrm{CQ}+\mathrm{SP}$ or $\mathrm{AQ}+\mathrm{SP}$. However, increasing resistance to these options in the early 2000s led to recommendations for the adoption of Artemisinin Combination Therapy (ACT) [5,6]. Consequently, either Artemether-Lumefanthrine (AL), ArtesunateAmodiaquine (ASAQ) or later Dihydro-artemisinin-Piperaquine (DHA-PQP) were adopted as first-line or alternative first line regimens for treating uncomplicated falciparum malaria in nearly all countries in Africa. In 2004, Uganda adopted AL as the first line regimen and two years later added ASAQ as the alternative first line regimen, with quinine as the second line regimen $[7,8]$.

Quinine was the first established antimalarial medicine, and has been used to treat malaria for centuries [9]. Intravenous quinine was for many decades the standard therapy for severe falciparum malaria in all African countries. Many malaria endemic countries that adopted ACT as first-line therapy recommended quinine as the second line regimen for uncomplicated malaria despite clear guidance from the World Health Organisation (WHO) that antimalarial medicines should be used in combination [10]. Until recently, 29 of the 41 subSaharan African countries that used ACT as the first-line treatment for uncomplicated malaria also recommended quinine as second line therapy [11]. Moreover, due to decreased efficacy of older medicines and the limited availability of ACT, quinine became increasingly used as a first-line medicine for treating uncomplicated malaria in Africa, especially in the private sector. For example, a survey conducted in 2007 in four districts in Uganda showed that quinine was prescribed for $4 \%$ of all patients with uncomplicated malaria [12]. A similar survey that year, at Mulago hospital, the national referral hospital in Kampala, showed that quinine was prescribed for $26 \%$ of diagnosed cases of uncomplicated malaria [13]. Thus, although quinine may not be listed as a first-line regimen for treating uncomplicated malaria in many countries, it continues to be widely used. Recent trials have demonstrated that intravenous Artesunate has superior efficacy in treating severe malaria [14,15], and it is anticipated that this practice will change. However, strong pharmacovilance systems will be required to document the magnitude of isolated episodes of late haemolytic anaemia that has been observed in some settings with intravenous Artesunate [16].

\section{Methods and Literature}

We reviewed published and un-published literature about malaria case management, drug policy and antimalarial drug resistance in Uganda for the period 1970 to 2013. Our objectives were to provide a historical overview and evolution of the malaria case management strategies and drug policies in Uganda from the period after the era of the Global Malaria Eradication Programme (GMEP) to the present roll back malaria-RBM era. This review was motivated by a need to: a) capture a historical perspective of the malaria case management strategies and drug policies so as to draw lessons for today's control ambitions; and b) maintain an institutional memory of the last few decades of malaria case management policies in Uganda - who was involved, what was done, what worked and more importantly what did not work. Online electronic literature databases were used as one means for identifying peer-reviewed published papers on malaria case management in Uganda. Due to its wide coverage of the biomedical literature, PubMed [http://www.ncbi.nlm.nih.gov/sites/entrez] was used as the basis for all the initial online searches of published sources. In addition, we used the World Health Organization (WHO) library database [http://www.who.int/library]; and the African journals online (AJOL) [http://www.ajol.info]. In all digital electronic database searches for published work the free text keywords "malaria" and "Uganda" were used. We avoided using specialised medical subject headings (MeSH) terms in digital archive searches to ensure as wide as possible the search inclusion. Further, we reviewed national malaria control programme documents at the ministry of health headquarters in Kampala, Uganda and requested the worldwide antimalarial resistance network (WWARN) to provide standardized analyses of ACT efficacy data in the WWARN repository (www. wwarn.org).

\section{Review Findings}

\section{Malaria control 1970-1995: apathy to renewed interest}

The malaria eradication experiments conducted in Uganda in the 1950s and 1960s, targeting adult vectors or parasites, provided in some cases impressive findings of the impact on malaria transmission [17-19]. However, following the abandonment of the eradication goal in Africa after the recommendation of WHO in 1969 [20], there was a general sense of disappointment and apathy globally and nationally which was associated with a decline in resource allocation for malaria. Uganda's malaria program collapsed due to lack of human and financial resources. During the period 1970 to 1990, a period of great civil and political turmoil in Uganda, there was little effort to control malaria, resulting in a resurgence of the disease. The years of civil strife left the entire Ugandan health system in disrepair. The malaria control programme lost critical programme staff and the malaria centre at Jinja in eastern Uganda was left in ruins. Efforts to revamp Uganda's health sector in the early 1980s were hampered by rampant insecurity and a de-motivated work force. The only malaria control effort was presumptive treatment with CQ. There was no policy and no strategic plan. From 1986 onwards, Uganda as a country started making some recovery, including a gradual economic growth. However, there was no matched improvement in the health indicators during this period. It was not until the early 1990s, when the global efforts to control malaria were re-started, that malaria gained some greater national prominence. In 1992, a global malaria control strategy aimed at preventing mortality and reducing morbidity was adopted by the health ministerial conference held in Amsterdam. This strategy was adopted by the World Health Assembly (WHA) in 1993 as the global strategy for malaria control [21]. During this period there was hardly any malaria research in Uganda, despite the efforts of the WHO's tropical disease research (WHO-TDR) in other countries. The only significant malaria research leading up to 1995 was undertaken in two western Uganda districts (Kabarole and Bundibugyo), supported by the German development cooperation (GTZ). These studies were important in providing contemporary data on the epidemiology and micro-epidemiology of malaria in Uganda, assessing the knowledge, attitudes and practices towards malaria with an emphasis on how communities understood treatment and prevention as well as estimates of malaria specific mortality rates in different endemicity zones [22].

\section{Uganda's malaria control 1995-2001: defining the challenge}

After the endorsement of the global malaria strategy by the WHA in 1993 [21], Uganda's malaria control efforts started gaining some visibility. In the early 1990s, Uganda's ministry of health (MoH) conducted an analysis of the malaria control problems in the country and revealed the following challenges: lack of integration and intersectoral collaboration in control; problems with case management due to self-medication and the wide availability of antimalarials on the 
Citation: Ambrose OT, Jane A, Albert PO, Adoke Y, Fred K, et al. (2014) The Changing Landscape of Malaria Case Management in Uganda: Decades of Struggle with Evolving Malaria Case Management Strategies and Drug Policies. Malar Chemoth Cont 3: 117. doi: $10.4172 / 2090-2778.1000117$

Page 3 of 16

open market; failure of vector control and environmental management, partly due to the efficient transmission characteristics of the major vectors and the multiplicity of breeding sites, but also lack of environmental management planning; absence of trained personnel; lack of an information system for monitoring and evaluation; inadequate early detection of malaria epidemics; escalating drug resistance of Plasmodium falciparum to CQ; and lack of resources [23].

In 1995, a burden of disease (BOD) study conducted in 13 of the districts supported by the World Bank found that $75 \%$ of the life years lost to premature death in Uganda were due to ten preventable diseases, including perinatal and maternal related conditions, malaria, acute respiratory infections, HIV/AIDS, tuberculosis, and diarrhoea [24]. However, the resource allocation for malaria was not commensurate with this disease burden. Faced with these statistics, the $\mathrm{MoH}$, in 1995, established a Malaria Control Unit (MCU).

In 1996, two years prior to the launch of the RBM initiative, the World Bank initiated funding to support malaria control efforts in several African countries. Between 1996 and 1999 the World Bank, WHO and UNICEF led missions to six countries: Kenya, Mozambique, Tanzania, Ethiopia, Malawi and Uganda. In Uganda, the team met with key stakeholders including: government officials, health sector staff, researchers, Non-Governmental Organizations (NGOs) and manufacturers. The mission highlighted the impact of malaria in Uganda and concluded that malaria control activities should be integrated within existing and proposed World Bank operations in the country. However, existing resources were being under-utilized, as the public health sector did not have the capacity to absorb available funding [25]. While these joint missions were a practical step towards creating a national partnership around malaria, it became very clear that partnerships would not establish themselves naturally and crosssectoral approaches were not well-institutionalized. After the 1996 joint mission, malaria did become more recognized as a national priority and the country developed the first five year malaria strategic plan (MSP) (1996-2001) and a three year malaria policy. The plan was launched under the banner "the Uganda Intensified Malaria Control Initiative" [23]. The strategy emphasized the importance of early diagnosis and effective treatment of malaria in all areas, including improving laboratory components. Importantly, it was recognized that implementation had to be through the district health care system in collaboration with other agencies within the communities. It was hoped that there would be significant investment in improving the information platform, through the health management information system (HMIS), to provide evaluation metrics and help define epidemic thresholds for early detection. At the time the intensified malaria control initiative was launched, a complimentary anti-malaria policy was developed and adopted in 1998 [26]. The aims in the policy followed those of the MSP but retained several historic elements of malaria control, including environmental sanitation and the destruction of breeding places where feasible. The policy also covered the treatment of malaria with $\mathrm{CQ}$ as the first line regimen, sulphadoxine-pyrimethamine (SP) as the second line regimen and quinine as the medicine for severe malaria and for cases resistant to CQ or SP. The policy further stated that chemoprophylaxis could be useful for first and second time pregnancies, patients with sickle cell disease and visitors from non-endemic countries. The antimalarial policy recommended that legislation should be made on proper mosquito control especially in urban areas and identified priority research, including monitoring treatment efficacy and drug sensitivity, monitoring the quality of antimalarial drugs present in the country and a broader economic and cost effectiveness analysis [26].

\section{Restructuring Uganda's malaria control unit, the malaria zonal coordination system and staff turn over}

After the development of the first MSP (1996-2001), there was restructuring of the MCU and an organogram developed composed of the following sections: Program management, deputy program management/in charge for malaria case management, epidemiology, epidemic preparedness and control, research and data management, vector control and environmental management and information, education, communication (IEC)/behavioural change communication (BCC). Supporting these sections were two technical advisors provided by the German development cooperation and the UK's department for international development (DFID).

In line with Uganda's 1993 policy of decentralization, the first anti malarial policy recommended the creation of a functional level called zonal coordination centres to support the decentralized districts in the implementation of malaria control. These coordination centres were based at the eleven regional referral hospitals. At the district level, an officer was assigned the additional responsibility of serving as a malaria focal person. The operations of the zonal coordinators was initiated in 1998 and their overall objective was to assist the national level in providing support to districts with respect to coordination, planning, implementation, supervision, monitoring and evaluation of malaria control activities. The support to malaria control in the districts was guided by the national MSP. This system of zonal coordination was to be jointly implemented from 1998 with the existing programme for integrated management of childhood illnesses (IMCI) $[27,28]$. However, insufficient funds for the operational costs of this system of integrated support prevented its smooth functioning.

Uganda's malaria control programme has over the years witnessed an alarming turnover of staff. Between 1997 and 2013 there have been seven different programme managers. A technical advisor who joined the programme in 1998, left in 2004, while another seconded by DFID in 2000 left in 2003, was replaced by yet another who also left in 2005. The MCU organogram was further reviewed and re-defined in 2001 and the programme was transformed into a national malaria control programme (NMCP) with four technical working groups (TWGs) [28]. These TWGs were supposed to report to the inter-agency coordinating committee (ICCM). In 2004, with support from various development partners including the Global Fund (GF) and the Malaria Consortium [Www.malariaconsortium.org] the zonal system was revitalized and played a significant role in supervision, training and in improving data collection and quality of malaria case management. In 2004, the concept of the zonal coordination system was re-defined, the criteria for selection/ appointment of coordinators set and resource requirements estimated; the terms of reference for the zonal coordinators were clearly stipulated; the 11 coordination zones were demarcated and all vacant positions filled [29].

\section{Grappling with antimalarial drug resistance and the first antimalarial drug policy change}

Effective uncomplicated malaria treatment during the mid-late 1990s was complicated by the emergence of resistance to widely used antimalarial medicines such as CQ. There had been no reports (suspected or confirmed) of Plasmodium falciparum resistance to CQ or amodiaquine (AQ) before 1969. In 1969, following a report of 
Citation: $\quad$ Ambrose OT, Jane A, Albert PO, Adoke Y, Fred K, et al. (2014) The Changing Landscape of Malaria Case Management in Uganda: Decades of Struggle with Evolving Malaria Case Management Strategies and Drug Policies. Malar Chemoth Cont 3: 117. doi: $10.4172 / 2090-2778.1000117$

Page 4 of 16

reduced CQ sensitivity from the missionary hospital at Kuluva in West Nile, a field study was conducted. 160 children attending Eruba primary school, 180 children attending Vurra primary school and 90 children attending Kuluva missionary hospital were examined for the presence of malaria parasites daily following standard body weight CQ three day dosing [29]. The trial found that CQ eliminated parasitaemia before the 5th day post-treatment with a large majority clearing parasites on the 3rd day, suggesting normal sensitivity of falciparum malaria to CQ in Kuluva [29]. Between 1970 and the early 1980s there were hardly any drug efficacy studies conducted. However, over the period 1988-2001, several in vivo efficacy studies were conducted with different protocols, different study populations and different outcome measures [30-43], (Table 1). Many of the studies conducted before 1996 used asymptomatic subjects attending schools as recommended by the then WHO protocols [44], while those conducted after 1996 recruited symptomatic patients aged between 6 and 59 months or all age groups [45].

Faced with the lack of standardization of drug efficacy methodology and the limited sharing of data generated in the late 1990s, the East African Network for Monitoring Antimalarial Treatment (EANMAT) was conceived, in 1997, in response to the sub-region's growing need for reliable information on the sensitivity of malaria parasites to antimalarial drugs. The goal of the network was to ensure that rational and evidence based malaria treatment policies were implemented in the East African sub-region. The network began with Kenya, Uganda and Tanzania (mainland), and was joined later by Rwanda, Burundi and Zanzibar [46,47]. Initially the majority of the efficacy test data collection and analysis in Uganda was done by the MCU in collaboration with the staff at eight sentinel health facilities (Figure 1) [48-51]. However, in view of the complexities required to conduct these studies, a model based on collaboration with local research partners was adopted after the formation, in 2000, of the Uganda malaria surveillance programme (UMSP).

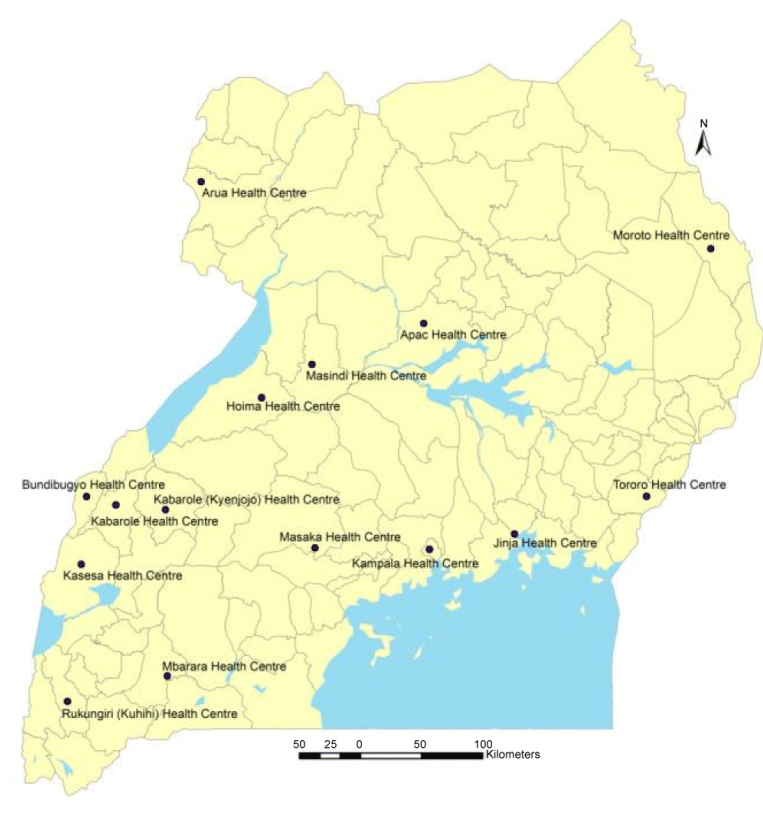

Figure 1: MCU in collaboration with the staff at eight sentinel health facilities.
The data generated by the EANMAT/UMSP sentinel surveillance and several other studies conducted in Uganda confirmed that the prevalence of CQ resistance had become a major problem. For the period 1999-2001, CQ treatment failures had reached an average of $33 \%$, based on a 14 day follow up in children less than five years old (Table 1). While SP mono-therapy treatment failure had increased from $5.5 \%$ to $12 \%$ for the period $1995-1998$ (Table 1). Paradoxically, faced with these data, the $\mathrm{MOH}$ changed the first-line treatment policy at the end of 2000 to a combination of CQ+SP [52], which had an average failure rate of $7 \%$ at the time the policy was launched. This interim solution was adopted because there was a perceived lack of practical alternatives. Treatment guidelines and other training and communication materials were updated, supplies of SP increased to support CQ co-administration and all health staff in the public sector trained on the new treatment guidelines. Following the 2000 decision, the actual launch of the policy took place in April 2002 and by 2003 practically all government health facilities used CQ+SP for malaria treatment. In contrast, uptake was significantly slower in the private sector where in September 2002 only 15\% of all shops had both, CQ and SP available [53].

\section{The second antimalarial treatment policy change and implementation}

As had been anticipated, resistance to $\mathrm{SP}$ as well as CQ+SP continued to rise and reached an average of $16 \%$ and $12 \%$ treatment failure at day 28 of follow-up respectively during the period 2002-2004 $[43,49,50]$. The announcement that CQ+SP would be abandoned in favour of Artemether-Lumefanthrine (AL) was first made on 17th May 2004. Interestingly at this time the data available on AL efficacy from Epicentre at Mbarara were not used by the $\mathrm{MoH}$ to arrive at this decision and the new policy seems to have been arrived at as a default position using principally decisions made by the neighbouring countries-Kenya, Tanzania and Rwanda, who were members of the sub-regional network-EANMAT. Further, there was a general reluctance to adopt Amodiaquine (AQ) combinations because of the safety concerns for AQ in the region. The adoption of the new ACT policy was predominantly based on their presumed good efficacy and the likely long useful life-expectancy with low probabilities of resistance. However, the affordability, acceptability, adherence and feasibility remained uncertain. The national malaria programme (NMCP) promoted a vision for ACT of "learning while doing". The Global Fund (GF) round 4 provided approximately US\$ 66 million within the US\$ 158 million award to accelerate the implementation of the new AL treatment policy, which included funds to purchase AL for the public sector, strengthen distribution systems, train over 5,000 health workers in the new policy during the first year and maintain supervision in the second year. DFID-UK provided funds to the Malaria Consortium to support the NMCP in this difficult drug policy transition and implementation. 
Citation: Ambrose OT, Jane A, Albert PO, Adoke Y, Fred K, et al. (2014) The Changing Landscape of Malaria Case Management in Uganda: Decades of Struggle with Evolving Malaria Case Management Strategies and Drug Policies. Malar Chemoth Cont 3: 117. doi: $10.4172 / 2090-2778.1000117$

Page 5 of 16

\begin{tabular}{|c|c|c|c|c|c|c|c|}
\hline \multirow{3}{*}{ Study districts } & \multirow{3}{*}{ Year of study } & \multirow{3}{*}{\begin{tabular}{|l|} 
Subjects recruited, Age group \\
[follow-up duration]
\end{tabular}} & \multirow{2}{*}{\multicolumn{2}{|c|}{ Parasitological failure (\%) }} & \multirow{2}{*}{$\begin{array}{l}\text { Clinical } \\
\text { failure (\%) }\end{array}$} & \multirow{2}{*}{ Treatment } & \multirow{3}{*}{ Reference } \\
\hline & & & & & & & \\
\hline & & & $\mathrm{CQ}$ & SP & $\mathrm{CQ}$ & SP & \\
\hline \multirow{2}{*}{ Kampala } & \multirow{2}{*}{1988} & Asymptomatic, & \multirow{2}{*}{39} & \multirow{2}{*}{0} & \multirow{2}{*}{ - } & \multirow{2}{*}{ - } & \multirow{2}{*}{ [30] } \\
\hline & & $5-15$ years [7 days] & & & & & \\
\hline \multirow{2}{*}{ Jinja } & \multirow{2}{*}{1988} & Asymptomatic, & \multirow{2}{*}{23} & \multirow{2}{*}{0} & \multirow{2}{*}{ - } & \multirow{2}{*}{ - } & \multirow{2}{*}{ [30] } \\
\hline & & $5-15$ years [7 days] & & & & & \\
\hline \multirow{2}{*}{ Masaka } & \multirow{2}{*}{1988} & Asymptomatic, & \multirow{2}{*}{38} & \multirow{2}{*}{0} & \multirow{2}{*}{ - } & \multirow{2}{*}{ - } & \\
\hline & & 5-15 years [7 days] & & & & & {$[30]$} \\
\hline & & Asymptomatic, & & & & & \\
\hline IViasinal & 1988 & $5-15$ years [7 days] & 29 & 10 & - & - & {$[30]$} \\
\hline & & Asymptomatic, & & & & & \\
\hline Kasese & 1988 & $5-15$ years [ 7 days] & 21 & 0 & - & - & [30] \\
\hline & & Asymptomatic, & & & & & \\
\hline Frud & 1500 & 5-15 years [7 days] & 3 & 10 & - & - & {$[30]$} \\
\hline Kabarole & 1992 & $\begin{array}{l}\text { Asymptomatic } \quad \text { and } \\
\text { uncomplicated, }\end{array}$ & 16 & 5 & - & - & [31] \\
\hline & & $0.5-60$ years [7 days] & & & & & \\
\hline & & Uncomplicated, & & & & & \\
\hline Kampala & 1993 & $0.5-5$ years [14 days] & 12 & 2 & - & - & [32] \\
\hline & 1000 & Uncomplicated, & & & & & \\
\hline Apac & 1993 & $0.5-5$ years [14 days] & 2 & 0 & - & - & {$[32]$} \\
\hline & & Uncomplicated, & & & & & \\
\hline & & 0.5-5 years [14 days] & & & & & \\
\hline Hoima & 1995 & Asymptomatic, & 58 & 4 & - & - & [33] \\
\hline & & 7-10 years [7 days] & & & & & \\
\hline ling & $10 x+2$ & Uncomplicated, & 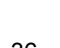 & 5 & 1 & $c_{1}+2$ & (2) \\
\hline JinId & 1590 & $0.5-5$ years [14 days] & 30 & $\mathrm{~J}$ & 12 & 0 & {$[04]$} \\
\hline & & Uncomplicated, & & & & 5 & \\
\hline Bundibugyo & 1996 & $0.5-5$ years [14 days] & 40 & 13 & 33 & 5 & [35] \\
\hline & & Uncomplicated, & & & & & \\
\hline Kabarole & 1996 & $0.5-5$ years [14 days] & 77 & 7 & 58 & 4 & [36] \\
\hline . & 1000 & Uncomplicated, & & $c$ & 10 & 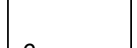 & 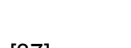 \\
\hline vinja & 1000 & $0.5-5$ years [14 days] & 00 & 0 & 12 & 0 & {$[0 T]$} \\
\hline & & Uncomplicated, & & & & & \\
\hline Jinja & 1998 & $0.5-5$ years [14 days] & 33 & 3 & 28 & 2.4 & [38] \\
\hline Tororo & 1999 & Uncomplicated, & 88 & 72 & 21 & 15 & [38] \\
\hline
\end{tabular}


Citation: $\quad$ Ambrose OT, Jane A, Albert PO, Adoke Y, Fred K, et al. (2014) The Changing Landscape of Malaria Case Management in Uganda: Decades of Struggle with Evolving Malaria Case Management Strategies and Drug Policies. Malar Chemoth Cont 3: 117. doi: $10.4172 / 2090-2778.1000117$

Page 6 of 16

\begin{tabular}{|c|c|c|c|c|c|c|c|}
\hline & & $0.5-5$ years [ 14 days] & & & & & \\
\hline \multirow{2}{*}{ Arua } & \multirow{2}{*}{1999} & Uncomplicated, & \multirow{2}{*}{43} & \multirow{2}{*}{19} & \multirow{2}{*}{21} & \multirow{2}{*}{10} & \multirow{2}{*}{ [38] } \\
\hline & & $0.5-5$ years [ 14 days] & & & & & \\
\hline \multirow{2}{*}{ Apac } & \multirow{2}{*}{$1998 / 99$} & Uncomplicated, & \multirow{2}{*}{41} & \multirow{2}{*}{14} & \multirow{2}{*}{15} & \multirow{2}{*}{10} & \multirow{2}{*}{ [38] } \\
\hline & & $0.5-5$ years [14 days] & & & & & \\
\hline \multirow{2}{*}{ Rukungiri } & \multirow{2}{*}{$1998 / 99$} & Uncomplicated, & \multirow{2}{*}{10} & \multirow{2}{*}{0} & \multirow{2}{*}{10} & \multirow{2}{*}{0} & \multirow{2}{*}{ [38] } \\
\hline & & $0.5-5$ years [ 14 days] & & & & & \\
\hline \multirow{2}{*}{ Kabarole } & \multirow{2}{*}{$1998 / 99$} & Uncomplicated, & \multirow{2}{*}{81} & \multirow{2}{*}{20} & \multirow{2}{*}{44} & \multirow{2}{*}{13} & \multirow{2}{*}{ [38] } \\
\hline & & $0.5-5$ years [ 14 days] & & & & & \\
\hline \multirow{2}{*}{ Moroto } & \multirow{2}{*}{1998} & Uncomplicated, & \multirow{2}{*}{ - } & \multirow{2}{*}{ - } & \multirow{2}{*}{48} & \multirow{2}{*}{12} & \\
\hline & & $0.5-5$ years [ 14 days] & & & & & [0 \\
\hline & & Uncomplicated, & & & & & \\
\hline a fiviolo & (1900 & $0.5-5$ years [14 days] & & 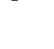 & 21 & 政 & {$[39]$} \\
\hline & & Asymptomatic, & & & & & \\
\hline Horma & 1998 & $4-10$ years [7 days] & 28 & 1 & - & - & {$[40]$} \\
\hline & & Uncomplicated, & & & & & \\
\hline Mbarara & 1998/99 & $0.5-5$ years [ 14 days] & - & - & 81 & 25 & {$[41]$} \\
\hline Kamnala & $1098 / 99$ & Uncomplicated, & 83 & & 62 & & [12] \\
\hline namilpold & (190/99 & $0.5-5$ years [14 days] & 00 & - & 02 & - & {$[4<]$} \\
\hline & & Uncomplicated, & & & & & \\
\hline 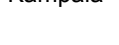 & 然 & $0.5-5$ years [14 days] & - & 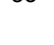 & 10 & 11 & {$[+0]$} \\
\hline & & Uncomplicated, & & & & & \\
\hline 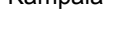 & 1959<0 & $0.5-5$ years [14 days] & - & - & 20 & 14 & {$[40]$} \\
\hline
\end{tabular}

Table 1: CQ and SP resistance studies among children in Uganda (1988-2001).

Problems of effective national consensus following the announcement were similar to those faced by Kenya during this period [54]. These centred around the ability of the Uganda government to finance the long-term supply of AL, single source issues around the Novartis-WHO agreement, the reported global shortages of Artemisinin to produce $\mathrm{AL}$ and the possible interruption in manufacture by Novartis Pharma. In July 2005 the policy statement was revised to be more inclusive of other ACT, notably AQ +Artesunate. The policy therefore stated: "The recommended first line medicine is Artemether/Lumefantrine. This medicine (Artemether/ Lumefantrine) is not recommended for children below 4 months of age or $5 \mathrm{kgs}$ body weight and pregnant women in the first trimester. Artesunate + Amodiaquine is the alternative when Artemether/ Lumefantrine is not available" [52]. Oral Quinine was designated the second line treatment for all patients and also for pregnant women with clinical malaria [52]. It was not until 9th September 2005, that the NMCP organized a dissemination workshop to introduce the new policy to a wider set of stakeholders; 80 attendees including members of the iCCM, MoH senior staff members, National Drug Authority (NDA), Ugandan associations of paediatricians, private practitioners, medical associations, the research community, malaria zonal coordinators, integrated management of childhood illness-IMCI and its zonal coordinators and the $\mathrm{MoH}$ units responsible for reproductive health and health education and promotion. Various delays occurred in re-developing the national standard treatment guidelines (STG) but the revised policy supporting AL in the public sector was eventually launched in health facilities in May 2006 with the new STG, postcascade training and emergency funding to procure AL. All implementation activities therefore started 24 months after the policy change was announced; and complete roll out of the new policy for the first line treatment occurred by the end of 2006 [55].

\section{Monitoring ACT resistance}

Between 2002 and 2012, 13 ACT efficacy studies with 28 days of follow up were undertaken at six sites (Table 2) [56-73]. Overall the median PCR adjusted day 28 efficacy for AL was $98 \%$ (range: $71.9 \%-$ $100 \%)$ showing that this drug remains effective (Table 3). However, slow clinical and parasitological response with ACT for treating uncomplicated $P$. falciparum malaria has emerged in Western 
Citation: $\quad$ Ambrose OT, Jane A, Albert PO, Adoke Y, Fred K, et al. (2014) The Changing Landscape of Malaria Case Management in Uganda: Decades of Struggle with Evolving Malaria Case Management Strategies and Drug Policies. Malar Chemoth Cont 3: 117. doi: $10.4172 / 2090-2778.1000117$

Page 7 of 16

Cambodia and may have independently emerged or spread to other sites in the Mekong region [74,75]. Tracking the evolution of artemisinin resistance is of paramount importance in Africa [76,77]. The WHO recommends that the proportion of patients remaining parasite positive at day 3 exceeding $10 \%$ should serve as a definition for suspected resistance [78], while others suggest a resistance rule out threshold of 3\% [79].

\begin{tabular}{|c|c|c|c|c|c|}
\hline Study site and year started & $\mathbf{N}$ & Malaria transmission intensity & $\begin{array}{l}\text { Days of follow } \\
\text { up }\end{array}$ & PubMed ID & Reference \\
\hline Kampala, 2002 & 400 & Moderate & 28 & 15567011 & [56] \\
\hline Mbarara, 2006 & 304 & Moderate & 42 & 20932805 & [57] \\
\hline Mbarara, 2002 & 957 & Moderate & 28 & 15850630 & [58] \\
\hline Tororo, 2004 & 408 & High & 28 & 16871329 & [59] \\
\hline Mbarara, 2005 & 577 & High & 42 & 19936217 & {$[60]$} \\
\hline Apac, 2002 & 542 & High & 28 & 16033307 & [61] \\
\hline Arua, 2002 & 534 & High & 28 & 16033307 & [61] \\
\hline Jinja, 2002 & 543 & Moderate & 28 & 16033307 & [61] \\
\hline Tororo, 2002 & 541 & High & 28 & 16033307 & [61] \\
\hline Kampala, 2001 & 448 & Low-Moderate & 14 & 12641399 & [62] \\
\hline Apac, 2006 & 421 & High & 42 & 17525792 & [63] \\
\hline Kanungu, 2006 & 414 & Moderate & 42 & 18545692 & [64] \\
\hline Kampala, 2007 & 175 & Moderate & 28 & 19622553 & [65] \\
\hline Tororo, 2008 & 232 & High & 28 & 19877969 & [66] \\
\hline Kampala, 2004 & 1409 & Moderate & 28 & 20689585 & [67] \\
\hline Tororo, 2007 & 584 & High & 28 & 22087077 & [68] \\
\hline Jinja, 2007 & 496 & Low & 28 & 22087077 & [68] \\
\hline Mbarara, 2007 & 404 & Moderate & 28 & 22087077 & [68] \\
\hline Bundibugyo, 2002 & 178 & High & 28 & 15078262 & [69] \\
\hline Tororo, 2007 & 218 & High & 28 & 23349741 & 70 \\
\hline Amudat, 2003 & 212 & Moderate & 28 & Unpublished & Epicentre \\
\hline Kampala, 2008 & 416 & Moderate & 42 & Unpublished & Sanofi \\
\hline
\end{tabular}

Table 2: Summary of antimalarial drug efficacy studies in Uganda, 2001-2013, Source: WorldwideAntimalarial Drug Reisistance NetworkWWARN.

\begin{tabular}{|l|l|l|l|l|l|}
\hline \multirow{2}{*}{ Study ID } & \multirow{2}{*}{$\mathbf{N}$} & D28Efficacy & \multirow{2}{*}{$\mathbf{9 5 \%} \mathbf{C l}$} & D28Efficacy & \multirow{2}{*}{ 95\% Cl } \\
\cline { 3 - 6 } & & adjusted & & unadjusted & \\
\hline Mbarara_2002 & 957 & 99.9 & $99.2-100$ & 96.5 & $95.1-97.5$ \\
\hline Kampala_2004 & 579 & 99.8 & $98.8-100$ & 95.4 & $93.3-96.9$ \\
\hline Tororo_2004 & 204 & 96 & $91.1-98.2$ & 34.2 & $27.7-40.7$ \\
\hline Mbarara_2005 & 191 & 96.4 & $89.1-98.8$ & 79.7 & $69.7-86.7$ \\
\hline Kanungu_2006 & 199 & 97.4 & $93.9-98.9$ & 83.1 & $77.0-87.7$ \\
\hline Mbarara_2006 & 152 & 99.3 & $95.4-99.9$ & 99.3 & $95.4-99.9$ \\
\hline
\end{tabular}


Citation: $\quad$ Ambrose OT, Jane A, Albert PO, Adoke Y, Fred K, et al. (2014) The Changing Landscape of Malaria Case Management in Uganda: Decades of Struggle with Evolving Malaria Case Management Strategies and Drug Policies. Malar Chemoth Cont 3: 117. doi: $10.4172 / 2090-2778.1000117$

Page 8 of 16

\begin{tabular}{|l|l|l|l|l|l|}
\hline Apac_2006 & 210 & 100 & $98.3-100$ & 69.8 & $63.0-75.5$ \\
\hline Tororo_2007b & 35 & 92.3 & $71.9-98.1$ & 41.8 & $25.3-57.5$ \\
\hline Jinja_2007 & 227 & 98 & $95.7-99.2$ & 94.1 & $89.9-96.6$ \\
\hline Tororo_2007a & 221 & 95.8 & $91.8-97.9$ & 57.5 & $50.6-63.8$ \\
\hline Kampala_2007 & 89 & 100 & & 95.9 & $87.8-97.7$ \\
\hline Tororo_2008 & 113 & 100 & $96.8-100$ & 80 & $71.2-86.4$ \\
\hline Kampala_2008 & 205 & 97.9 & $93.9-99.1$ & 52.5 & $45.4-59.2$ \\
\hline
\end{tabular}

Table 3: D28 adjusted and un adjusted treatment efficacy AL.

The Worldwide Antimalarial Resistance Network (WWARN) [www.wwarn.org] has conducted a systematic review to search for the individual patient level data from clinical efficacy studies (available online). As of June 2013, there were 25 studies in the WWARN data repository from Uganda undertaken between 2000 and 2010, comprising 12,098 patients. Based on these data there seems to be no evidence suggesting artemisinin resistance (delayed parasite clearance) at any of the Ugandan sites. No site and no treatment regimen (AL, Amodiaquine -Artesunate-ASAQ or Dihydro ArtemisininPiperaquine-DHAPQP) had a point estimate of the proportion with persistent parasitemia at day 3 exceeding 3\% (Figures 2-4). However, the coverage of drug resistance surveillance sites needs to be further improved to reduce nationwide data gaps, especially in the North Eastern part of the country (Figure 5). Further, none of the existing studies employ rich parasite density sampling which might be required to detect emerging Artemisinin resistance. The latter is now planned under the East Africa Public Health Laboratory Network project (EAPHLNP) which is supported by the World Bank [http:// www.eac.int/health/index.php].

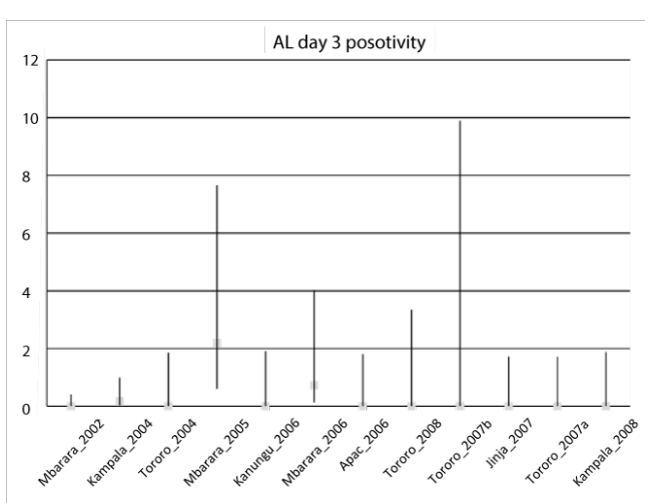

Figure 2: (AL, Amodiaquine -Artesunate-ASAQ or Dihydro Artemisinin-Piperaquine-DHAPQP) had a point estimate of the proportion with persistent parasitemia at day 3 exceeding $3 \%$.

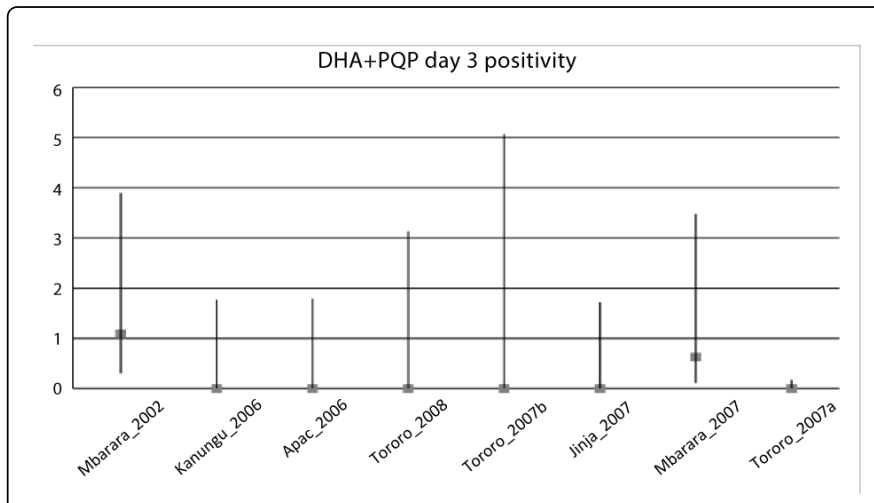

Figure 3: (AL, Amodiaquine -Artesunate-ASAQ or Dihydro Artemisinin-Piperaquine-DHAPQP) had a point estimate of the proportion with persistent parasitemia at day 3 exceeding $3 \%$.

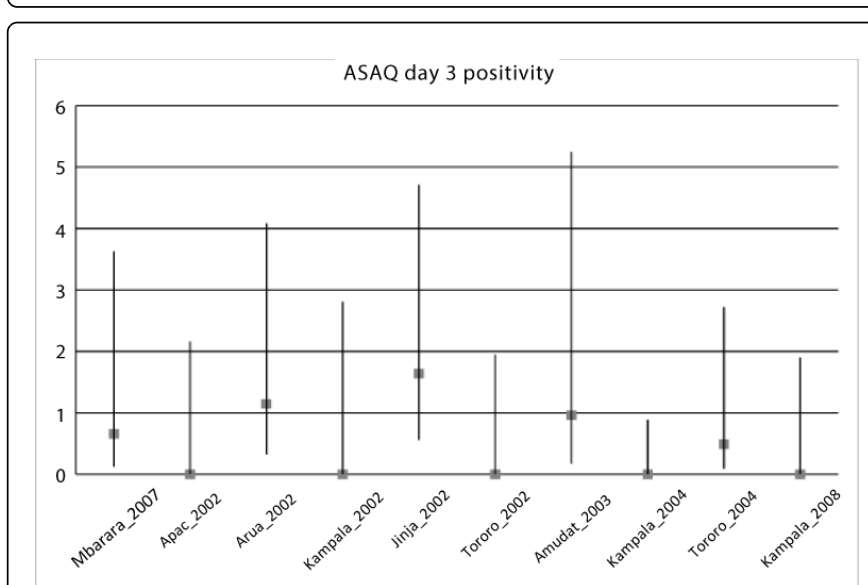

Figure 4: (AL, Amodiaquine -Artesunate-ASAQ or Dihydro Artemisinin-Piperaquine-DHAPQP) had a point estimate of the proportion with persistent parasitemia at day 3 exceeding $3 \%$. 
Citation: $\quad$ Ambrose OT, Jane A, Albert PO, Adoke Y, Fred K, et al. (2014) The Changing Landscape of Malaria Case Management in Uganda: Decades of Struggle with Evolving Malaria Case Management Strategies and Drug Policies. Malar Chemoth Cont 3: 117. doi: $10.4172 / 2090-2778.1000117$

Page 9 of 16

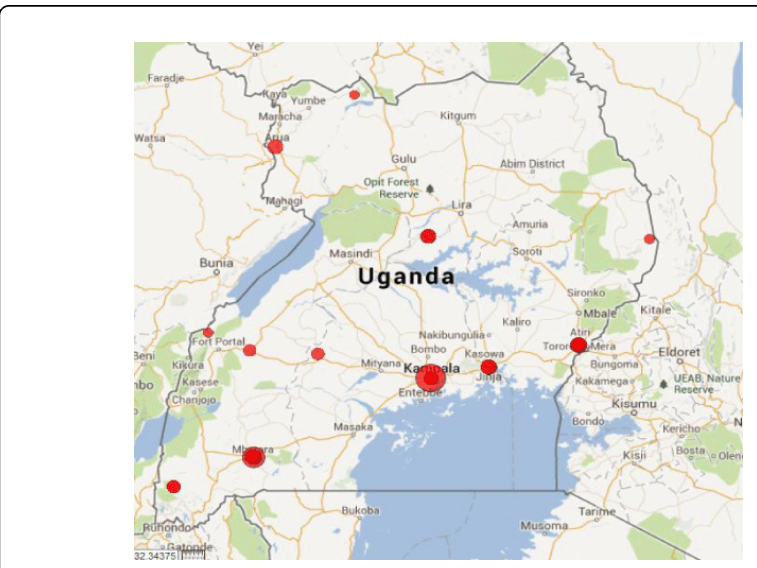

Figure 5: North Eastern part of the country.

\section{Grappling with sub-standard and counterfeit medicines}

A major concern during the early years of the malaria case management policy in Uganda was the quality of medicines available in the private sector. In 1997, the drug regulatory body, the National Drug Authority (NDA), sampled 12 quinine mixtures/syrups from nine local manufacturers and found that none of them produced quinine in standard strengths (i.e. 100-mg quinine base $/ 5 \mathrm{mls}$ ) [80]. In 1998 , a study of the quality of CQ reported that up to $30 \%$ of the tablet samples and $33 \%$ of the injectable CQ samples contained less than the normal amount of the active ingredient; only $45 \%$ of tablet samples and $38 \%$ of injectable samples of CQ contained the normal amount of active ingredient [81]. A major challenge for Uganda remains the weak system for post marketing surveillance and pharmacovigilance [82]. To date, the use of counterfeit artemisinin combination therapy (ACT) medicines remains a very real threat to emerging resistance and the lack of effective pharmacovigilance is a major weakness. In a recent study between 2010 and 2011, at 93 drug stores in five Ugandan districts, 558 ACT products were tested using Raman spectroscopy and $39 \%$ were shown to be fakes [83].

\section{Bridging the access to treatment gap-Home based management of fever (HBMF)}

After several studies trying to improve malaria case management at home [84-86], in 1998, WHO-TDR spearheaded pilot studies to assess the feasibility of using pre-packaged medicines for home based management of malaria fevers (HBMF). The first pilot countries were Ghana, Nigeria and Uganda. In Uganda the pilot studies were conducted between 1998 and 2000, in three districts. The studies demonstrated that HBMF was feasible and could improve access to malaria treatment [87]. Consequently, HBMF was adopted as a policy in 2001 [88]. In order to complement the availability of free malaria treatment through public health facilities and bring it closer to the home, the programme of HBMF for children less than 5 years of age was introduced initially in 10 districts in 2002 [89]. The blister packed combination treatment of CQ+SP was developed in two agedependent and colour-coded packages; one for children 6 months to 2 years and another for the 2-5 year olds. The treatment was branded "HOMAPAK" and was produced by a local pharmaceutical company. The medicines were initially distributed directly to the districts by the NMCP but delivery was later integrated into the existing essential medicines supply system. Caregivers of children with fever accessed the treatment through volunteers called Community Drug Distributors (CDD) or Community Medicine Distributors (CMD), two of whom were selected and trained per village (approximately 500 people). These CDDs/CMDs reported to and received supplies from the nearest health facility which was also responsible for supervision.

Rolling out of the HBMF strategy continued between 2003 and 2006 and was assisted by the GF Round 2 and Round 4 funding. A 2003 evaluation of the HBMF program found an increase from 7\% in 2001 to $39 \%$ of febrile children receiving malaria treatment within 24 hours in nine districts receiving the HBMF intervention. By 2005, HBMF had been scaled-up across communities in 47 districts, including the internally displaced persons (IDP) camps in the North of the country [90-92]. The approach was widely researched and it was generally felt to be an effective vehicle to ensure malaria medicines were close to the household when needed for prompt treatment [93-95]. However, HBMF faced many challenges, including: an inability to sustain the initial motivation of the volunteers due to lack of remuneration or other incentives; inability to ensure adequate supervision, data flows and drug supply management challenges; problems associated with being a vertical programme with inadequate integration with other community-based health activities such as IMCI; and finally an inability to transition to the new treatment policy in 2004-2007 using ACT. The latter had regulatory challenges beyond the NMCP, for example whether community volunteers were allowed to handle the new drug whose safety remained uncertain and there was no pharmacovigilance linked to HBMF. Moreover, an alternative strategy became more popular, with a focus on integrated community case management (iCCM) and several assessment studies were conducted in the country that demonstrated that iCCM was feasible $[96,97]$. ICCM using ACT is presently implemented in only 34 of 112 districts.

\section{Challenges during the ACT era and improving access to treatment in the private sector}

The private sector supports first treatment contact for an estimated $40-50 \%$ of fevers $[98,99]$. As HBMF is yet to be scaled up nationwide for $\mathrm{AL}$, engaging private sector providers was seen as a key element of improving AL access. In 2008, the consortium for ACT private sector subsidy (CAPSS) pilot project introduced a subsidized, first-line AL product in the private sector in Uganda. Four intervention districts were purposefully selected to receive branded subsidized medicines, while the fifth district acted as a control. Products in the intervention districts were branded " $A C T$ with a leaf" to distinguish them from all other ACTs and antimalarials. A maximum recommended retail price (MRRP) for each age-pack was printed on the product. The final price per age-pack ranged from US\$ 0.10 to US\$ $0.40[100,101]$. At baseline, ACT accounted for less than $1 \%$ of anti-malarials purchased from licensed drug shops for children less than five years old but at the end of the pilot "ACT with a leaf' accounted for $69 \%$ of anti-malarial purchased in the interventions districts [101].

A broader initiative to increase nation-wide AL availability through the private sector was launched in 2010 by the GF's Affordable Medicines Facility for malaria (AMFm) initiative [102-104]. Uganda was part of the pilot 10 -country study. AMFm negotiated with manufacturers to reduce the price of their ACT, offered a co-payment of approximately $95 \%$, reducing the factory price of ACT to US\$ 0.05 per adult dose. In-country national importers/wholesalers and retailers worked out an affordable profit margin to ensure affordable quality assured $\mathrm{AL}$ to consumers at the periphery through drug shops and 
Citation: $\quad$ Ambrose OT, Jane A, Albert PO, Adoke Y, Fred K, et al. (2014) The Changing Landscape of Malaria Case Management in Uganda: Decades of Struggle with Evolving Malaria Case Management Strategies and Drug Policies. Malar Chemoth Cont 3: 117. doi: $10.4172 / 2090-2778.1000117$

Page 10 of 16

general shops. Based on the CAPSS experience in Uganda, the AMFm products were branded "ACT with a leaf". However, AMFm elected not to print the maximum recommended retail price for each agepack. The AMFm independent evaluation for Uganda indicated a high achievement on the indicator for availability of quality assured ACTs (QAACTs) which rose from $21 \%$ to $67 \%$ and medium achievement on the indicator for market share of QAACTs, which rose from $40 \%$ to $57 \%$. However, there was poor achievement on the indicator for price of QAACTs US\$ 1.96 vs. US\$ $0.59[102,103]$.

The Uganda AMFm was not as successful as the CAPSS pilot project largely because the grant amendment was signed late because of an initial objection from the Uganda government that AMFm would "kill" local pharmaceuticals companies. Further, the scope, scale and intensity of the demand generation under the Uganda AMFm were sub-optimal compared to that of the CAPSS pilot project. After the AMFm phase 1 independent evaluation report was presented to the Global Fund [102,103], the Global Fund Board decided to integrate the AMFm into core Global Fund grant management and financial processes. AMFm phase 1 countries such as Uganda were encouraged to incorporate AMFm-like strategies within their broader funding requests and national strategies. How this might evolve as true private sector integration continues to pose a challenge in Uganda and raises major concerns [105].

\section{Improving Malaria Diagnosis}

Repeated attempts were made to improve the availability and the quality of laboratory diagnosis for malaria through training and provision of microscopes. The proportion of health facilities with functional microscopy services modestly increased over the second MSP period (2001-2005); only 8\% of all cases reported in the HMIS in 2004 were laboratory confirmed. In 2009 this had increased to $17 \%$ [106] and to $24 \%$ by 2010 [107-109]. Based on the confirmed RDTs quantities available in the country and the shift to voluntary pooled procurement - VPP delivery schedules, the country seems to be on track to achieve the 2015 diagnostics targets. However, regular supervision and quality control of laboratory services in the public sector has been insufficient or absent. Rapid diagnostic tests (RDTs) for Plasmodium falciparum have been repeatedly investigated to assess their accuracy and feasibility at peripheral health facilities in the public, private and community level [110-123]. Most of the studies found RDTs to be useful in settings where no laboratories were available. While RDTs have been routinely used for the investigation of suspected malaria outbreaks and by some NGOs in the context of clinical services in the IDP camps in Northern Uganda, they need to be quickly scaled up in the public sector and at community level. In 2007, the WHO and $\mathrm{MoH}$ with support from DFID to the Malaria Consortium provided an in-country forum to debate and provide a road map for scaling up the use of diagnostics for malaria [124]. Late in 2009, a further consensus meeting proposed the scale-up of RDTs at lower level health facilities and the community level starting as operational research [125]. Numerous local and international NGO and agencies provided technical support in the development of implementation tools, including a trainer's manual, user's guides, job aids and quality control frameworks. A central coordination and steering committee was established and was responsible for planning, quantifying and providing leadership to the role-out of universal parasite diagnosis. The roll-out of diagnostics and the large scale use of RDTs by village health teams-VHTs was launched in 2010 under the iCCM strategy in mid western and central Uganda; this initiative led to a sharp rise in the use of malaria diagnostics for febrile patients from $8 \%$ to $30 \%$ during 2010 [126].

A major strategic shift in 2011 was the expansion of parasite diagnosis in the management of malaria in line with WHO recommendations for Test, Treat and Track-T3 [127]. The policy and STGs on malaria case-management were subsequently changed from presumptive treatment to parasite based diagnosis and treatment [128]. With this new policy it is likely that RDT scale up will be rapid and the aim is to ensure that there are microscopy services at all health facilities from level III and above and RDTs at health centres II-HC II and community levels and to fill the gaps at higher level health facilities whenever microscopy services are not possible.

\section{Improving malaria case management commodity tracking}

An initiative to improve malaria drug management, malaria diagnosis and treatment in the public sector, mTRAC, was piloted in 2010 in two districts [129]. mTRAC uses internet or mobile phone SMS based interfaces to enhance real time reporting on various malaria indicators including the availability of ACTs, Quinine and RDTs stocks, malaria cases confirmed by microscopy or RDTs, malaria cases treated and other health service delivery monitoring indicators. MTrac has now been adopted beyond the pilot districts.

\section{Quality of malaria case management (uncomplicated and severe)}

\section{Uncomplicated malaria}

Treatment guidelines and training curricula have been developed and health workers trained on malaria case management by the $\mathrm{MOH}$ and partners. However, the availability and the proper use of the recommended medicines at peripheral health facilities has been challenging. A survey done in four districts in 2008 revealed that there were often stock-outs of the recommended drugs. $13 \%$ of the facilities reported complete lack of AL in the two weeks preceding the survey, and even when drugs were present, clinicians prescribed nonapproved therapies, including CQ, SP and CQ+SP in $18 \%$ of patients [12]. Further, the 2009 malaria indicator survey reported that among children under five years with fever, $60 \%$ took an anti-malarial medicine, and of these, only $23 \%$ took an ACT.

\section{Severe malaria}

In the previous couple of years, several activities have been undertaken to enhance the effective management of severe malaria, including: the use of Artesunate suppositories administered close-tohome under ICCM; revision of the training manuals for severe malaria; as well as efforts to make relevant supplies available at referral health facilities. Clinical audits have also been used in an attempt to improve the operational efficiency and quality in the management of severe malaria in 34 pilot districts. However the management of severe malaria remains sub-optimal. A cross sectional survey, conducted in 2009, in 11 districts in the eastern and mid-western parts of Uganda documented the following: none of the inpatient facilities had all seven components of the basic care package for the management of severe malaria consistently available in the 3 months prior to the survey. Referral practices were appropriate for less than $10 \%$ of the patients [130]. Prompt care at any health facility was reported by only $29 \%$ of patients. Severe malaria was correctly diagnosed in $27 \%$ of patients. Though the quinine dose and regimen was correct in the majority 
Citation: $\quad$ Ambrose OT, Jane A, Albert PO, Adoke Y, Fred K, et al. (2014) The Changing Landscape of Malaria Case Management in Uganda: Decades of Struggle with Evolving Malaria Case Management Strategies and Drug Policies. Malar Chemoth Cont 3: 117. doi: $10.4172 / 2090-2778.1000117$

Page 11 of 16

(70.4\%) of patients, it was administered in the correct volumes of 5\% dextrose in only $18 \%$ of the patients. Most patients (80.1\%) had several doses of quinine administered in one single $500 \mathrm{ml}$ bottle of $5 \%$ dextrose. Further, medications were purchased by $44 \%$ of the patients and medical supplies by $70.6 \%$ of the patients. The authors of the survey concluded that the management of severe malaria in Ugandan health facilities was sub-optimal. Priority areas for improvement were identified as: triage and emergency care, referral practices, quality of diagnosis and treatment, availability of medicines and supplies, training and support supervision [130] (Table 4).

\begin{tabular}{|l|l|l|l|l|l|}
\hline \multirow{2}{*}{ Study ID } & \multirow{2}{*}{$\mathbf{N}$} & D28Efficacy & \multirow{2}{*}{$\mathbf{9 5 \%} \mathbf{C l}$} & D28Efficacy & \multirow{2}{*}{$\mathbf{9 5 \%} \mathbf{C l}$} \\
\cline { 3 - 6 } & & adjusted & & unadjusted \\
\hline Mbarara_2005 & 386 & 98.9 & $95.7-99.7$ & 91.7 & $86.6-94.9$ \\
\hline Kanungu_2006 & 215 & 99.1 & $93.6-99.8$ & 96.2 & $92.6-98.1$ \\
\hline Apac_2006 & 211 & 100 & $98.3-100$ & 89 & $83.9-92.5$ \\
\hline Tororo_2007b & 72 & 93.6 & $90.2-99.8$ & 77.5 & $65.9-85.6$ \\
\hline Jinja_2007 & 227 & 98.6 & $95.6-99.5$ & 96.6 & $93.0-98.4$ \\
\hline Mbarara_2007 & 159 & 99.3 & $95.3-99.9$ & 93.9 & $88.5-96.8$ \\
\hline Tororo_2007a & 220 & 95.7 & $91.9-97.7$ & 75.5 & $69.2-80.7$ \\
\hline Tororo_2008 & 119 & 100 & $96.9-100$ & 96.6 & $91.1-98.7$ \\
\hline
\end{tabular}

Table 4: D28 adjusted and un adjusted treatment efficacy for DHA-PQP.

An malaria programme review-MPR conducted in 2011 identified the following issues with respect to malaria case management in Uganda [131]: frequent stock-outs of antimalarial medicines and supplies at health facilities and community level; although the NMCP had conducted training of health workers in 21 districts on the use of RDTs, implementation was hampered by non-availability of RDTs; integrating private sector providers into national case management programme was a major challenge; there were weak services for management of severe malaria below HCIV level; poor laboratory personnel staffing at all levels; inadequate technical supervision to service delivery points; obsolete equipment (microscopes); inadequate linkages with the regional and district laboratory focal persons; lack of a malaria reference laboratory; inadequate staffing, inadequate knowledge, skills and attitudes; piecemeal and fragmented implementation of activities in the era of universal coverage (e.g. HBMF, amidst weak facility systems); inadequate collaboration mechanisms with private facilities and inadequate job aids and guidelines in the health facilities (Table 5).

\begin{tabular}{|l|l|l|l|l|l|}
\hline \multirow{2}{*}{ Study-Site } & \multirow{2}{*}{$\mathbf{N}$} & D28Efficacy & \multirow{2}{*}{$\mathbf{9 5 \%}$ Cl } & D28Efficacy & \multirow{2}{*}{$\mathbf{9 5 \%}$ CI } \\
\cline { 3 - 5 } & & adjusted & & unadjusted \\
\hline Apac_2002 & 174 & 89.6 & $83.2-93.6$ & 46.5 & $38.9-53.8$ \\
\hline Arua_2002 & 174 & 92.2 & $86.6-95.5$ & 49.3 & $41.7-56.6$ \\
\hline Kampala_2002 & 134 & 96.7 & $91.3-98.7$ & 82.2 & $74.4-87.8$ \\
\hline Jinja_2002 & 189 & 95.8 & $91.4-98.0$ & 80.1 & $73.5-85.2$ \\
\hline Tororo_2002 & 194 & 87.6 & $79.3-92.7$ & 25.5 & $19.4-32.0$ \\
\hline Amudat_2003 & 106 & 95.7 & $88.8-98.4$ & 27.3 & $19.1-36.1$ \\
\hline Kampala_2004 & 434 & 98.7 & $97.0-99.5$ & 93 & $89.9-95.1$ \\
\hline Tororo_2004 & 204 & 93.1 & $87.9-96.4$ & 49.8 & $42.7-56.4$ \\
\hline Mbarara_2007* & 160 & 98.6 & $94.6-99.7$ & 85.6 & $78.7-90.4$ \\
\hline Kampala_2008* & 208 & 99 & $95.9-99.7$ & 52.3 & $45.1-59.0$ \\
\hline
\end{tabular}

Table 5: D28 adjusted and un adjusted treatment efficacy for ASAQ. 
Citation: $\quad$ Ambrose OT, Jane A, Albert PO, Adoke Y, Fred K, et al. (2014) The Changing Landscape of Malaria Case Management in Uganda: Decades of Struggle with Evolving Malaria Case Management Strategies and Drug Policies. Malar Chemoth Cont 3: 117. doi: $10.4172 / 2090-2778.1000117$

Page 12 of 16

\section{Changing funding landscape for malaria case management strategies}

In submitted a successful malaria proposal to the Round 2 call for proposals and another successful application to the Round 4 call in 2004. The round $4 \mathrm{GF}$ funding, over US\$ 150 million, was targeted at procuring ACT and RDTs and supporting HBMF. In August 2005 the GF suspended all funding (Rounds 2 and 4) to Uganda following a Pricewaterhouse Coopers financial audit highlighting gross mismanagement of funds [132]. The government of Uganda appointed Ernst \& Young as GF managers including responsibilities for procurement of commodities. Following several months of lobbying and reorganizing the national GF management system, the GF ban was lifted in November 2005. The Malaria Consortium and the WHO were active participants in ensuring that the suspension would not interrupt activities deemed to be life-saving such as procurement of $\mathrm{AL}$ and the operational costs to support health worker training. In 2005, the United States Government announced a new five-year, US\$
1.2 billion initiative to rapidly scale-up malaria prevention and treatment interventions in high-burden countries in sub-Saharan Africa, known as the President's Malaria Initiative (PMI) [http:// www.fightingmalaria.gov/]. Fortunately, when GF funding had been suspended, the country became one of the first of three countries to benefit from this new PMI funding and began with "jump start" funding of circa US\$500,000 in 2005. In 2006, PMI awarded US\$ 9.5 million to Uganda, which increased to between US\$ 19 million and US \$ 35 million per annum between 2007 and 2013 [133]. In 2010, the GF awarded additional funds under Round 10, US\$ 156 million, for the procurement of ACT and RDTs [134]. Therefore, between 2005 and 2010, Uganda had an unprecedented access to malaria development assistance, able to transform how successful the malaria case management strategies would be relative to previous periods. However, there was also a rapid turnover of staff within the malaria programme and universal access to malaria case management was never achieved (Table 6).

\begin{tabular}{|l|l|l|l|}
\hline No & Description of Indicator & Target & Achieved \\
\hline 1 & Proportion of malaria cases with confirmed diagnosis by microscopy or RDTs & $85 \%$ by 2015 & $24 \%$ \\
\hline 2 & Proportion of the districts with at least $80 \%$ of targeted HWs trained on RDT & $100 \%$ & $22.8 \%$ \\
\hline 3 & $\begin{array}{l}\text { Proportion of districts with at least } 80 \% \text { of targeted laboratory technicians trained on malaria } \\
\text { microscopy }\end{array}$ & $100 \%$ & $38.3 \%$ \\
\hline 4 & Number of health facilities participating in malaria slide rechecking (EQA) & 200 by 2015 & 60 \\
\hline 4 & Proportion of the population accessing effective treatment with 24 hours of symptom onset & $85 \%$ by 2015 & $30 \%$ \\
\hline
\end{tabular}

Table 6: Status of achievement on the indicators for malaria diagnosis and treatment.

\section{Malaria control 2010-2015: sustaining the gains}

In 2010, Uganda defined its fourth MSP (2010-2015) [135], tied to Uganda's broader development context as detailed in its Vision 2040 [136] and the national development plan [137]. The government of Uganda, with the stewardship of the $\mathrm{MoH}$, developed the third National Health Policy (NHP III) that covers a five year period 2010/11-2014/2015 and includes malaria as part of the minimum essential package. The MSP has as its vision "Malaria will no longer be the major cause of illness and death in Uganda and families will have universal access to malaria prevention as well as treatment by 2015". The overall goals of the 2010-2015 MSP are two-fold: 1) to control and prevent malaria morbidity and mortality, and thereby minimize the social effects and economic losses attributable to malaria in the country; and 2) to contribute to the reduction of under-five all-cause mortality rate, as a result of reduced malaria mortality. The case management related objectives are to: provide a definitive diagnosis to at least $85 \%$ of suspected malaria cases in the public sector; provide effective ACT treatment to at least $85 \%$ of people with uncomplicated malaria within 24 hours of onset of symptoms in the public or private sectors; provide preventive treatment to pregnant women with at least two doses of IPT with a safe antimalarial; create an enabling environment for the implementation of key malaria interventions through behavioural change initiatives, obtain adequate financing and appropriate human resources, conduct relevant operational research, strengthen M\&E and overall health systems [138]. Despite these broad ambitions, access to effective and prompt malaria case management remains sub-optimal in Uganda. During the national household survey of $2011,43 \%$ of febrile children took an antimalarial on the same/next day of symptom onset, with still only $30 \%$ of fevers treated with AL [139].

\section{Conclusion and Perspectives for the Future}

The evolution of Uganda's malaria case management strategies and drug policies has been a journey mirrored by its social and political struggles. The significance of malaria as a barrier to the country's development was evidenced by pre-independence urban control approaches and was resurrected as a development priority by the World Bank in the 1990s. There has been no shortage of timely research evidence that replacing failing mono-therapies can reduce malaria risk and reverse trends in disease burden. However, malaria case management interventions of proven efficacy have all struggled to achieve ubiquitous and equitable coverage despite their promotion in national strategic plans since the late 1990s. Arguably, the slow progress was a direct consequence of poor funding and a rapid turnover of staff leading to a constant loss of institutional memory within the national programme-seven NMCP heads since 1996. Significant official development assistance only became available from 2006 onwards, yet by 2013, there remained important gaps in national ambitions for universal coverage of malaria case management services.

Since 1996, when Uganda developed the first malaria strategic plan (MSP), post the malaria pre-eradication era, the country has developed three other MSPs- all in line with broad WHO recommendations to scale up effective diagnosis and treatment coverage universally. However, Uganda has struggled to scale up implementation nationwide. A major challenge noted by all previous reviews is the low profile 
Citation: $\quad$ Ambrose OT, Jane A, Albert PO, Adoke Y, Fred K, et al. (2014) The Changing Landscape of Malaria Case Management in Uganda: Decades of Struggle with Evolving Malaria Case Management Strategies and Drug Policies. Malar Chemoth Cont 3: 117. doi: $10.4172 / 2090-2778.1000117$

Page 13 of 16

of the NMCP within the MoH structure which limits its capacity and capability to coordinate multiple stakeholders in the country. Secondly there is limited involvement of the decentralised structures and the community in planning and implementation. In order for the country to rapidly achieve universal coverage of malaria diagnosis and treatment, there is a need for reforms in the profile and structure of the NMCP to facilitate better coordination of all malaria case management stakeholders. Further, there is a need for decentralized planning and implementation with greater involvement of the zonal, district, health facility and community levels. Moreover, it will critical to engage the challenging but very important private sector.

Finally, we believe such historical overviews should be periodically conducted to provide a form of institutional memory to current and future players in malaria case management in Uganda, highlighting some of the historical and current challenges for universal access to prompt and effective malaria case management.

\section{Acknowledgements}

We would like to thank Prof. RW Snow for early discussions on the idea for the review and for the critical review of the draft manuscripts. We are very grateful to the Worldwide Antimalarial Resistance Network-WWARN for generating the Uganda malaria drug resistance profile that has been partly used for the ACT drug efficacy and early parasitological response analysis presented in this review. This work was funded by UK's Department for International Development-DFID in phase one of the epidemiological profiles in 8 countries, including Uganda. AOT is supported by funding provided by MRC/DfID/ Wellcome Trust Joint Global Health Trial scheme (Grant \# MR/ K007351/1).

\section{Author Contributions}

AOT conceived the idea and did the literature search. All the authors reviewed the first draft manuscript and approved the final version.

\section{References}

1. World Health Organization (2013) World Malaria Report, WHO, Geneva.

2. Okello PE, Van Bortel W, Byaruhanga AM, Correwyn A, Roelants P, et al. (2006) Variation in malaria transmission intensity in seven sites throughout Uganda. Am J Trop Med Hyg 75: 219-225.

3. Yeka A, Gasasira A, Mpimbaza A, Achan J, Nankabirwa J, et al. (2012) Malaria in Uganda: challenges to control on the long road to elimination: I. Epidemiology and current control efforts. Acta Trop 121: 184-195.

4. Onori E, Benthein F (1967) An investigation of the annual cycle of malaria in an area of Uganda.

5. WHO (2001) Antimalarial Drug Combination Therapy. Report of a WHO Technical Consultation. World Health Organization: Geneva.

6. Attaran A, Barnes KI, Curtis C, d'Alessandro U, Fanello CI, et al. (2004) WHO, the Global Fund, and medical malpractice in malaria treatment. Lancet 363: 237-240.

7. Ministry of Health (2005) National Policy on Malaria Treatment, Malaria Control Programme, Ministry of Health, Kampala, Uganda.

8. Ministry of Health (2010) Revised National Policy on Malaria Treatment, Malaria Control Programme, Ministry of Health, Kampala, Uganda.

9. P Rosenthal (2001) Antimalarial Chemotherapy: Mechanisms of Action, Resistance, and New Directions in Drug Discovery, in The history of antimalarial drugs, M.S.a.D. MJ, Human Press. 15-25.
10. Qazi SA, Muhe LM (2006) Integrating HIV management for children into the Integrated Management of Childhood Illness guidelines. Trans R Soc Trop Med Hyg 100: 10-13.

11. P Olumese (2008) Antimalarial treatment policies for P. falciparum and P. vivax by country in WHO Africa region in Anti-Malarial Drug Policies. WHO, AFRO.

12. Zurovac D, Tibenderana JK, Nankabirwa J, Ssekitooleko J, Njogu JN, et al. (2008) Malaria case-management under artemether-lumefantrine treatment policy in Uganda. Malar J 7: 181.

13. Uganda Malaria Surveillance Project (UMSP) (2010) Sentinel site report.

14. Dondorp AM, Fanello CI, Hendriksen IC, Gomes E, Seni A, et al. (2010) Artesunate versus quinine in the treatment of severe falciparum malaria in African children (AQUAMAT): an open-label, randomised trial. Lancet 376: 1647-1657.

15. World Health Organization (2010) Guidelines for the Treatment of Malaria, WHO, Geneva, Switzerland.

16. World Health Organization (2013) WHO Information Note on Delayed Haemolytic Anaemia following Treatment with Artesunate, WHO, Geneva, Switzerland.

17. De Zulueta J, Kafuko Gw, Cullen Jr, Pedersen Ck (1961) The results of the first year of a malaria eradication pilot project in Northern Kigezi (Uganda). East Afr Med J 38: 1-26.

18. De Zulueta J, Kafuko Gw, Cullen Jr (1963) AN INVESTIGATION OF THE ANNUAL CYCLE OF MALARIA IN MASAKA DISTRICT (UGANDA). East Afr Med J 40: 469-488.

19. Zulueta J, Kafuko Gw, Mccrae Aw, Cullen Jr, Pedrsen Ck, et al.. (1964) A Malaria Eradication Experiment In The Highlands Of Kigezi (Uganda). East Afr Med J 41: 102-120.

20. [No authors listed] (1969) Parasitology of malaria. Report of a WHO Scientific Group. World Health Organ Tech Rep Ser 433: 1-70.

21. [No authors listed] (1993) Implementation of the global malaria control strategy. Report of a WHO Study Group on the Implementation of the Global Plan of Action for Malaria Control 1993-2000. World Health Organ Tech Rep Ser 839: 1-57.

22. A. Kilian (1995) Malaria control in Kabarole and Bundibugyo districts western Uganda, Report on a comprehensive malaria situation analysis and design of a district control programme. Fort Portal, Uganda, Ministry of Health, Republic of Uganda and GTZ.

23. Ministry of Health (MOH) (1996) National Malaria Control Programme, Intensified Malaria Control Initiative.

24. Ministry of Health (MOH) (1996) Burden of Disease Study.

25. Talisuna AO (2008) Eradicating Malaria in IDB Member Countries, Islamic Development Bank Economic and Policy Department, Occasional paper No 13 Jamad Awwal $1429 \mathrm{H}$.

26. Ministry of Health (MOH) (1996) National Malaria Control Programme, Uganda Anti-Malarial Policy.

27. Kolstad PR, Burnham G, Kalter HD, Kenya-Mugisha N, Black RE (1997) The integrated management of childhood illness in western Uganda. Bull World Health Organ 75 Suppl 1: 77-85.

28. Ministry of Health, National Malaria strategic plan 2001-2005, Malaria Control Programme, Ministry of Health, Kampala, Uganda, 2000.

29. Onori E, Benthein F (1969) Investigation of alleged Chloroquine resistance of malaria parasites in Westnile district of Uganda, Parasitologia. 3: 225-234.

30. Sezi CL, Nevil CMA, Ochen K, Munafu C, Bek'obita D, (1991) The response of plasmodium to 4 aminoquinolines and pyrimethamine/ sulfadoxine at six sites scattered throughout Uganda. Uganda Medical Journal 8: 33-46.

31. Kamugisha J, Kipp W, Burnham G (1994) In vivo sensitivity of Plasmodium falciparum to chloroquine, amodiaquine and sulfadoxinepyrimethamine in western Uganda. Trop Geogr Med 46: 364-365.

32. Ministry of Health (1993) Report on the sensitivity of Chloroquine and Sulphadoxine-Pyrimethamine. Unpublished document. 
Citation: $\quad$ Ambrose OT, Jane A, Albert PO, Adoke Y, Fred K, et al. (2014) The Changing Landscape of Malaria Case Management in Uganda: Decades of Struggle with Evolving Malaria Case Management Strategies and Drug Policies. Malar Chemoth Cont 3: 117. doi: $10.4172 / 2090-2778.1000117$

Page 14 of 16

33. Ndyomugyenyi R, Magnussen P (1997) In vivo sensitivity of Plasmodium falciparum to chloroquine and sulfadoxine-pyrimethamine in school children in Hoima district, western Uganda. Acta Trop 66: 137-143.

34. Ministry of Health (MOH) (1995) National Malaria Control Programme, Uganda Anti-Malarial Policy.

35. Kilian A (1998) Unpublished drug sensitivity data.

36. Mpeka B, Ndezi G (1996) Unpublished drug sensitivity data report.

37. Talisuna AO, Langi P, Bakyaita N, Egwang T, Mutabingwa TK. Watkins $\mathrm{W}$, et al. (2002) Intensity of malaria transmission, antimalarial-drug use and resistance in Uganda: what is the relationship between these three factors? Transactions of the Royal Society of Tropical Medicine \& Hygiene 96: 310-317.

38. East African Network for Monitoring Antimalarial Treatment (EANMAT) (2001) Monitoring antimalarial drug resistance within National Malaria Control Programmes: the EANMAT experience. Tropical Medicine \& International Health 6: 891-898.

39. Ndyomugyenyi R, Magnussen P (2000) In vivo sensitivity of Plasmodium falciparum to chloroquine and sulfadoxine-pyrimethamine among schoolchildren in rural Uganda: a comparison between 1995 and 1998. Acta Trop 76: 265-270.

40. Legros D, Johnson K, Houpikian P, Makanga M, Kabakyenga JK, Talisuna AO, et al. (2002) Clinical efficacy of chloroquine or sulfadoxinepyrimethamine in children under five from south-western Uganda with uncomplicated falciparum malaria, Transactions of the Royal Society of Tropical Medicine \& Hygiene 96: 199-201.

41. Dorsey G, Kamya MR, Ndeezi G, Babirye JN, Phares CR, et al. (2000) Predictors of chloroquine treatment failure in children and adults with falciparum malaria in Kampala, Uganda. Am J Trop Med Hyg 62: 686-692.

42. Kamya MR, Dorsey G, Gasasira A, Ndeezi G, Babirye JN, et al. (2001) The comparative efficacy of chloroquine and sulfadoxine-pyrimethamine for the treatment of uncomplicated falciparum malaria in Kampala, Uganda. Transactions of the Royal Society of Tropical Medicine \& Hygiene, 95: 50:55.

43. Staedke SG, Kamya MR, Dorsey G, Gasasira A, Ndeezi G, et al. (2001) Amodiaquine, sulfadoxine/pyrimethamine, and combination therapy for treatment of uncomplicated falciparum malaria in Kampala, Uganda: a randomised trial. Lancet 358: 368-374.

44. Prokopev Di (1965) Resistance Of Malaria Parasites To Drugs. Report Of A Who Scientific Group. World Health Organ Tech Rep Ser 296: 1-65.

45. World Health Organization/CTD (1996) Assessment of therapeutic efficacy of antimalarial drugs for uncomplicated malaria in areas with intense transmission. World Health Organization.

46. East African Network for Monitoring Antimalarial Treatment (EANMAT), Monitoring antimalarial drug resistance within National Malaria Control Programmes: the EANMAT experience, rop Med Int Health 6: 891-8.

47. East African Network for Monitoring Antimalarial Treatment (EANMAT) (2003) The efficacy of antimalarial monotherapies sulphadoxine-pyrimethamine and amodiaquine in East Africa: implications for sub-regional policy. Tropical Medicine \& International Health, 8: 860-867.

48. Talisuna AO (2004) Intensity of malaria transmission spread of Plasmodium falciparum resistant malaria and genetic markers for chloroquine and sulphadoxine-pyrimethamine resistance, Proefschrift voorgelegd voor het behalen van de graad van Doctor in de Medische Wetenschappen aan de Universiteit Antwerpen door.

49. Bakyaita N, Dorsey G, Yeka A, Banek K, Staedke SG, et al. (2005) Sulphadoxine-pyrimethamine plus Chloroquine or Amodiaquine for uncomplicated falciparum malaria: a randomized, multisite trial to guide national policy in Uganda. American Journal of Tropical Medicine \& Hygiene 72: 573-580.

50. Talisuna AO, Nalunkuma-Kazibwe A, Bakyaita N, Langi P, Mutabingwa TK, et al. (2004) Efficacy of sulphadoxine-pyrimethamine alone or combined with amodiaquine or chloroquine for the treatment of uncomplicated falciparum malaria in Ugandan children. Tropical Medicine \& International Health 9: 222-229.

51. Kamya MR, Bakyaita NN, Talisuna AO, Were WM, Staedke SG (2002) Increasing antimalarial drug resistance in Uganda and revision of the national drug policy. Trop Med Int Health 7: 1031-1041.

52. Ministry of Health (2005) National Policy on Malaria Treatment, Malaria Control Programme, Ministry of Health, Kampala, Uganda, September.

53. Commercial Market Strategies-CMS (2003) Availability and pricing of Anti-malarials in the private Sector in Uganda, A study by the Commercial Market Strategies Project.

54. Amin AA, Zurovac D, Kangwana BB, Greenfield J, Otieno DN, et al. (2007) The challenges of changing national malaria drug policy to artemisinin-based combinations in Kenya. Malar J 6: 72.

55. Nanyunja M, Nabyonga Orem J, Kato F, Kaggwa M, Katureebe C, et al. (2011) Malaria treatment policy change and implementation: the case of Uganda. Malar Res Treat 2011: 683167.

56. Staedke SG, Mpimbaza A, Kamya MR, Nzarubara BK, Dorsey G, et al. (2004) Combination treatments for uncomplicated falciparum malaria in Kampala, Uganda: randomised clinical trial. Lancet 364: 1950-1957.

57. Piola P, Nabasumba C, Turyakira E, Dhorda M, Lindegardh N, et al. (2010) Efficacy and safety of artemether-lumefantrine compared with quinine in pregnant women with uncomplicated Plasmodium falciparum malaria: an open-label, randomised, non-inferiority trial. Lancet Infectious Diseases.762-769.

58. Piola P, Fogg C, Bajunirwe F, Biraro S, Grandesso F, et al. (2005) Supervised versus unsupervised intake of six-dose artemetherlumefantrine for treatment of acute, uncomplicated Plasmodium falciparum malaria in Mbarara, Uganda: a randomised trial. Lancet 365: 1467-1473.

59. Bukirwa H, Yeka A, Kamya MR, Talisuna A, Banek K, et al. (2006) Artemisinin combination therapies for treatment of uncomplicated malaria in Uganda. PLoS Clin Trials 1: e7.

60. Bassat Q, Mulenga M, Tinto H, Piola P, Borrman S, et al. (2009) Dihydroartemisinin-piperaquine and artemether-lumefantrine for treating uncomplicated malaria in African children: a randomised, non inferiority trial.

61. Yeka A, Banek K, Bakyaita N, Staedke SG, Kamya MR, et al. (2005) Artemisinin versus nonartemisinin combination therapy for uncomplicated malaria: randomized clinical trials from four sites in Uganda. PLoS Medicine 2: e190.

62. Gasasira AF, Dorsey G, Nzarubara B, Staedke SG, Nassali A, et al. (2003) Comparative efficacy of aminoquinoline-antifolate combinations for the treatment of uncomplicated falciparum malaria in Kampala, Uganda. Am J Trop Med Hyg 68: 127-132.

63. Kamya MR, Yeka A, Bukirwa H, Lugemwa M, Rwakimari JB, et al. (2007) Artemether-lumefantrine versus dihydroartemisinin-piperaquine for treatment of malaria: a randomized trial. PLoS Clin Trials 2: e20.

64. Yeka A, Dorsey G, Kamya MR, Talisuna A, Lugemwa M, et al. (2008) Artemether-lumefantrine versus dihydroartemisinin-piperaquine for treating uncomplicated malaria: a randomized trial to guide policy in Uganda. PLoS One 3: e2390.

65. Achan J, Tibenderana JK, Kyabayinze D, Wabwire MF, Kamya MR, et al. (2009) Effectiveness of quinine versus artemether-lumefantrine for treating uncomplicated falciparum malaria in Ugandan children: randomised trial, British Medical Journal 339: b2763.

66. Arinaitwe E, Sandison TG, Wanzira H, Kakuru A, Homsy J, et al. (2009) Artemether-lumefantrine versus dihydroartemisinin-piperaquine for falciparum malaria: a longitudinal, randomized trial in young Ugandan children, Clin Infect Dis. 49: 1629-1637.

67. Clark TD, Njama-Meya D, Nzarubara B, Maiteki-Sebuguzi C, Greenhouse B, et al. (2010) Incidence of malaria and efficacy of combination antimalarial therapies over 4 years in an urban cohort of Ugandan children. PLoS One 5: e11759.

68. Four Artemisinin-Based Combinations (4ABC) Study Group (2011) A head-to-head comparison of four artemisinin-based combinations for 
Citation: $\quad$ Ambrose OT, Jane A, Albert PO, Adoke Y, Fred K, et al. (2014) The Changing Landscape of Malaria Case Management in Uganda: Decades of Struggle with Evolving Malaria Case Management Strategies and Drug Policies. Malar Chemoth Cont 3: 117. doi: $10.4172 / 2090-2778.1000117$

Page 15 of 16

treating uncomplicated malaria in African children: a randomized trial. PLoS Med 8: e1001119.

69. Checchi F, Piola P, Kosack C, Ardizzoni E, Klarkowski D, et al. (2004) Antimalarial efficacy of sulfadoxine-pyrimethamine, amodiaquine and a combination of chloroquine plus sulfadoxine-pyrimethamine in Bundi Bugyo, western Uganda. Trop Med Int Health 9: 445-450.

70. Yeka A, Tibenderana J, Achan J, D'Alessandro U, Talisuna AO (2013) Efficacy of quinine, artemether-lumefantrine and dihydroartemisininpiperaquine as rescue treatment for uncomplicated malaria in Ugandan children. PLoS One 8: e53772.

71. Priotto G, Kabakyenga J, Pinoges L, Ruiz A, Eriksson T, et al. (2003) Artesunate and sulfadoxine-pyrimethamine combinations for the treatment of uncomplicated Plasmodium falciparum malaria in Uganda: a randomized, double-blind, placebo-controlled trial. Trans R Soc Trop Med Hyg. 97:325-30.

72. Vora N, Greenhouse B, Rosenthal PJ, Tappero J, Dorsey G (2009) Artemether-lumefantrine versus dihydroartemisinin-piperaquine for falciparum malaria: a longitudinal, randomized trial in young Ugandan children. Clinical Infectious Diseases 49: 1629-1933.

73. Yeka A, Lameyre V, Kibuuka A, Mudangha F, Lukwago R Efficacy and Safety of fixed-dose Artesunate-Amodiaquine vs ArtemetherLumefantrine for Repeated Treatment of Uncomplicated Malaria in Ugandan Children. PLoS One (un press)

74. Noedl H, Se Y, Sriwichai S, Schaecher K, Teja-Isavadharm P, et al. (2010) Artemisinin resistance in Cambodia: a clinical trial designed to address an emerging problem in Southeast Asia. Clin Infect Dis 51: e82-89.

75. Dondorp AM, Nosten F, Yi P, Das D, Phyo AP, et al. (2009) Artemisinin resistance in Plasmodium falciparum malaria. N Engl J Med 361: 455-467.

76. White NJ (2010) Artemisinin resistance--the clock is ticking. Lancet 376: 2051-2052.

77. Talisuna AO, Karema C, Ogutu B, Juma E, Logedi J, et al. (2012) Mitigating the threat of artemisinin resistance in Africa: improvement of drug-resistance surveillance and response systems. Lancet Infect Dis 12: 888-896.

78. World Health Organization (2011) Global Plan for Artemisinin Resistance Containment (GPARC), Geneva.

79. Stepniewska K, Ashley E, Lee SJ, Anstey N, Barnes KI, et al. (2010) In vivo parasitological measures of artemisinin susceptibility. J Infect Dis 201: 570-579.

80. National Drug Authority (NDA) (1997) Survey of quinine mixtures available on the market. Unpublished Report of the NDA Uganda.

81. Ogwal-Okeng JW, Okello DO, Odyek O (1998) Quality of oral and parenteral chloroquine in Kampala. East Afr Med J 75: 692-694.

82. Talisuna AO, Staedke SG, D'Alessandro U (2006) Pharmacovigilance of antimalarial treatment in Africa: is it possible? Malar J 5: 50.

83. Björkman-Nyqvist M, Svensson J, Yanagizawa-Drott D (2013) The Market for (Fake) Antimalarial Medicine: Evidence from Uganda, Centre for Economic Policy Research, London.

84. Kengeya-Kayondo JF, Seeley JA, Kajura-Bajenja E, Kabunga E, Mubiru E, et al. (1994) Recognition, treatment seeking behaviour and perception of cause of malaria among rural women in Uganda. Acta Trop 58: 267-273.

85. Ghebreyesus TA, Witten KH, Getachew A, O'Neill K, Bosman A, et al. (1999) Community-based malaria control in Tigray, northern Ethiopia. Parassitologia 41: 367-371.

86. Kidane G, Morrow RH (2000) Teaching mothers to provide home treatment of malaria in Tigray, Ethiopia: a randomised trial. Lancet 356: 550-555.

87. Mpeka B, Tugume B, Kigongo C, Lutalo T, Lubanga R (2000) Developing and piloting interventions for appropriate home management of childhood fevers in Uganda. Unpublished report.

88. Ministry of Health (2002) Strategy for Home-Based Management of Fever/Malaria in Uganda; First Edition, Malaria Control Programme, Ministry of Health, Kampala, Uganda.
89. Ministry of Health (2006) Malaria Control Strategic Plan, 2005/06 2009/10, Malaria Control Programme, Ministry of Health, Kampala, Uganda.

90. Malaria Consortium, Supporting the Ministry of Health provide a malaria control emergency response to internally displaced populations in Gulu, Kitgum and Pader districts, Malaria Consortium, Kampala, Uganda, Final Quarter Report, 1 April 2003 - 31 July 2003.

91. Meek S, Kabwa PB, Kyomuhendo S (2005) Review of implementation of the home based management of fever strategy in UPHOLD-supported districts, Malaria Consortium, Final Report.

92. Kilian AH, Tindyebwa D, Gülck T, Byamukama W, Rubaale T, et al. (2003) Attitude of women in western Uganda towards pre-packed, unitdosed malaria treatment for children. Trop Med Int Health 8: 431-438.

93. Nshakira N, Kristensen M, Ssali F, Reynolds WS (2002) Appropriate treatment of malaria? Use of anti-malarial drugs for children's fevers in district medical units, drug shops and homes in eastern Uganda. Tropical Medicine \& International Health. 7: 309-316.

94. Nsungwa SJ, Källander K, Nsabagasani X, Namusisi K, Pariyo G, et al. (2004) Local fever illness classifications: implication for home management of malaria strategies. Tropical Medicine \& International Health 9: 1191-1199.

95. Källander K, Nsungwa-Sabiiti J, Peterson S (2004) Symptom overlap for malaria and pneumonia--policy implications for home management strategies. Acta Trop 90: 211-214.

96. Kallander K, Tomson G, Nsabagasani X, Sabiiti JN, Pariyo G, et al. (2006) Can community health workers and caretakers recognise pneumonia in children? Experiences from western Uganda. Transactions of Royal Society of Tropical Medicine \& Hygiene 100: 956-963.

97. Källander K, Tomson G, Nsungwa-Sabiiti J, Senyonjo Y, Pariyo G, et al. (2006) Community referral in home management of malaria in western Uganda: a case series study. BMC Int Health Hum Rights 6: 2.

98. Medicines for Malaria Venture (2007) Annual Report.

99. Medicines for Malaria Venture (2008) Annual Report.

100. Talisuna AO, Daumerie PG, Balyeku A, Egan T, Piot B, et al. (2012) Closing the access barrier for effective anti-malarials in the private sector in rural Uganda: consortium for ACT private sector subsidy (CAPSS) pilot study. Malar J 11: 356.

101. Talisuna A, Grewal P, Rwakimari JB, Mukasa S, Jagoe G, et al. (2009) Cost is killing patients: subsidising effective antimalarials. Lancet 374: 1224-1226.

102. The Global Fund (2012) Final Report of the Independent Evaluation of AMFm Phase 1.

103. Tougher S, ACTwatch Group, Ye Y, Amuasi JH, Kourgueni IA, Thomson R, et al. Effect of the Affordable Medicines Facility-malaria (AMFm) on the availability, price, and market share of quality-assured artemisinin-based combination therapies in seven countries: a beforeand-after analysis of outlet survey data. Lancet 380: 1916-1926.

104. Davis B, Ladner J, Sams K, Tekinturhan E, de Korte D, et al. (2013) Artemisinin-based combination therapy availability and use in the private sector of five AMFm phase 1 countries. Malar J 12: 135.

105. Talisuna AO, Adibaku S, Amojah CN, Amofah GK, Aubyn V, et al. (2012) The Affordable Medicines Facility-malaria--a success in peril. Malar J 11: 370.

106. Uganda Bureau of Statistics (UBOS) and ICF International Inc, Uganda Demographic and Health Survey 2011. Kampala, Uganda: UBOS and Calverton, Maryland: ICF International Inc, 2012.

107. Uganda Bureau of Statistics (UBOS) and ORC Macro, Uganda Demographic and Health Survey 2000-2001.Calverton, Maryland, USA: UBOS and ORC Macro, 2001.

108. Uganda Bureau of Statistics (UBOS), Uganda National Household Survey 2005-06. Kampala, Uganda, 2006.

109. Uganda Bureau of Statistics (UBOS) and ICF Macro, Uganda Malaria Indicator Survey 2009. Calverton, Maryland, USA: UBOS and ICF Macro, 2010 
Citation: $\quad$ Ambrose OT, Jane A, Albert PO, Adoke Y, Fred K, et al. (2014) The Changing Landscape of Malaria Case Management in Uganda: Decades of Struggle with Evolving Malaria Case Management Strategies and Drug Policies. Malar Chemoth Cont 3: 117. doi: $10.4172 / 2090-2778.1000117$

Page 16 of 16

110. Asiimwe C, Kyabayinze DJ, Kyalisiima Z, Nabakooza J, Bajabaite M, et al. (2012) Early experiences on the feasibility, acceptability, and use of malaria rapid diagnostic tests at peripheral health centres in Ugandainsights into some barriers and facilitators, Implementation Science 7: 5 .

111. Batwala V, Magnussen P, Nuwaha F (2010) Are rapid diagnostic tests more accurate in diagnosis of plasmodium falciparum malaria compared to microscopy at rural health centres? Malar J 9: 349.

112. Batwala V, Magnussen P, Nuwaha F (2011) Comparative feasibility of implementing rapid diagnostic test and microscopy for parasitological diagnosis of malaria in Uganda. Malar J 10: 373.

113. Cohen J, Fink G, Berg K, Aber F, Jordan M, et al. (2012) Feasibility of distributing rapid diagnostic tests for malaria in the retail sector: evidence from an implementation study in Uganda. PLoS One 7: e48296.

114. Dhorda M, Piola P, Nyehangane D, Tumwebaze B, Nalusaji A, et al. (2012) Performance of a histidine-rich protein 2 rapid diagnostic test, Paracheck $\mathrm{Pf}^{\oplus}$, for detection of malaria infections in Ugandan pregnant women. Am J Trop Med Hyg 86: 93-95.

115. Hopkins H, Oyibo W, Luchavez J, Mationg ML, Asiimwe C, et al. (2011) Blood transfer devices for malaria rapid diagnostic tests: evaluation of accuracy, safety and ease of use. Malar J 10: 30.

116. Kyabayinze DJ, Tibenderana JK, Odong GW, Rwakimari JB, Counihan H (2008) Operational accuracy and comparative persistent antigenicity of HRP2 rapid diagnostic tests for Plasmodium falciparum malaria in a hyperendemic region of Uganda. Malaria Journal 7: 221.

117. Kyabayinze DJ, Asiimwe C, Nakanjako D, Nabakooza J, Counihan H, et al. (2010) Use of RDTs to improve malaria diagnosis and fever case management at primary health care facilities in Uganda. Malar J 9: 200.

118. Kyabayinze DJ, Tibenderana JK, Nassali M, Tumwine LK, Riches C, et al. (2011) Placental Plasmodium falciparum malaria infection: operational accuracy of HRP2 rapid diagnostic tests in a malaria endemic setting. Malaria Journal 10: 306.

119. Mbonye AK, Lal S, Cundill B, Hansen KS, Clarke S, et al. (2013) Treatment of fevers prior to introducing rapid diagnostic tests for malaria in registered drug shops in Uganda. Malar J 12: 131.

120. Mbonye AK, Ndyomugyenyi R, Turinde A, Magnussen P, Clarke S, et al. (2010) The feasibility of introducing rapid diagnostic tests for malaria in drug shops in Uganda. Malar J 9: 367.

121. Mbonye AK, Magnussen $P$ (2013) Translating health research evidence into policy and practice in Uganda. Malar J 12: 274.

122. Mukanga D, Tiono AB, Anyorigiya T, Källander K, Konaté AT, et al. (2012) Integrated community case management of fever in children under five using rapid diagnostic tests and respiratory rate counting: a multi-country cluster randomized trial. American Journal of Tropical Medicine \& Hygiene 87: 21-29.
123. Mukanga D, Tibenderana JK, Peterson S, Pariyo GW, Kiguli J, et al. (2012) Access, acceptability and utilization of community health workers using diagnostics for case management of fever in Ugandan children: a cross-sectional study. Malar J 11: 121.

124. Ministry of Health, the Malaria Notice Board (NCPNB), National Malaria Control Programme, June -September 2006.

125. Ministry of Health, Health sector strategic plan III, 2010/11-2014/15, 2010.

126. Ministry of Health, National Policy on Malaria Treatment, Malaria Control Programme, Ministry of Health, Kampala, Uganda, March, 2009.

127. WHO, Parasitological confirmation of malaria diagnosis, Report of a WHO technical consultation, Geneva, 6-8, October 2009.

128. Ministry of Health, National guidelines for implementation of parasite based diagnosis of malaria, Malaria Control Programme, Ministry of Health, Kampala, Uganda, June 2013.

129. Asiimwe C, Gelvin D, Lee E, Ben Amor Y, Quinto E, et al. (2011) Use of an innovative, affordable, and open-source short message service-based tool to monitor malaria in remote areas of Uganda. Am J Trop Med Hyg 85: 26-33.

130. Achan J, Tibenderana J, Kyabayinze D, Mawejje H, Mugizi R, et al. (2011) Case management of severe malaria--a forgotten practice: experiences from health facilities in Uganda. PLoS One 6: e17053.

131. Roll Back Malaria (RBM) (2011) Uganda Malaria Programme Performance Review.

132. Kapiriri L, Martin DK (2006) The Global Fund Secretariat's suspension of funding to Uganda: how could this have been avoided? Bull World Health Organ 84: 576-580.

133. USAID, President's Malaria Initiative (PMI), Uganda, Malaria Operational Plan FY 2013.

134. The Global Fund to Fights HIV/AIDS, Tuberculosis and Malaria, Uganda round 10 Proposal (Approved), Consolidating Malaria Control, 2010

135. Ministry of Health (2010) Health sector strategic plan III, 2010/11-2014/15, 2010.

136. National Planning authority, Republic of Uganda, Vision 2040, 2007.

137. National Planning authority, Republic of Uganda, National Development Plan 2010/11-2014/15, 2010.

138. Ministry of Health, Malaria Control Strategic Plan, 2001/02 - 2004/05, Malaria Control Programme, Ministry of Health, Kampala, Uganda, April 2001.

139. Uganda Bureau of Statistics (UBOS) and ICF International Inc, Uganda Demographic and Health Survey 2011, Kampala, Uganda, UBOS and Calverton, Maryland: ICF International Inc., 2012 